\title{
Educação Ambiental Crítica: pesquisa-ação, participação, silêncios e "silenciamentos"
}

\author{
Eda Terezinha de Oliveira Tassara ${ }^{1}$ e Omar Ardans ${ }^{2}$ \\ Universidade de São Paulo
}

resumo $O$ artigo visa refletir sobre as implicações metodológicas de pesquisas comprometidas com a abordagem crítica da Educação Ambiental, inscrevendoas no quadro do paradigma científico da Teoria Crítica. Com base nesse enquadramento, aborda questões relativas à promoção da participação popular em investigações comprometidas com a pesquisa-ação, bem como à compreensão de silêncios e "silenciamentos" nelas manifestos, enfocando-os, à luz da natureza de suas produções, em categorias psicológicas, psicossociais, epistêmicas e políticas.

palavras-chave: Educação Ambiental Crítica, Teoria Crítica, Pesquisa-ação, Participação, Silêncios, "Silenciamentos"

abstract The article aims to reflect on the methodological implications of research studies committed to the critical approach of Environmental Education, inserting them in the framework of the scientific paradigm of Critical Theory. Based on this focus, it approaches issues related to the promotion of popular participation in investigations committed to action research, as well as questions concerning the understanding of the silences and "silencing" that are manifested in them. The latter are placed, in light of the nature of their productions, in psychological, psychosocial, epistemic and political categories.

key words: Critical Environmental Education, Critical Theory, Action Research, Participation, Silences, "Silencing”

1 LAPSI - Laboratório de Psicologia Sócio-Ambiental e Intervenção do Instituto de Psicologia da USP, lapsi@usp.br

${ }^{2}$ LAPSI - Laboratório de Psicologia Sócio-Ambiental e Intervenção do Instituto de Psicologia da USP, ardans@uol.com.br 
Em seu livro "The paradigm dialog", Egon Guba (1990) define paradigma metodológico de conhecimento como um conjunto de crenças e valores que orientam a ação. Segundo esse autor, os paradigmas científicos podem ser definidos de acordo com as respostas que oferecem às questões ontológicas, epistemológicas e de método de investigação e aceitação de verdades. A primeira refere-se à concepção da natureza do conhecimento; a segunda, à concepção da relação entre o sujeito e o objeto do conhecimento; e a terceira, ao método de acesso ao conhecimento decorrente, de forma coerente e consistente, das duas primeiras respostas às referidas questões. Dessa forma, o autor apresenta em sua obra as crenças relativas a quatro paradigmas vigentes na prática científica contemporânea, ou seja: o do positivismo, o do pós-positivismo, o da teoria crítica e o do construtivismo ou hermenêutica-dialética.

Guba, na obra anteriormente referida, considera o paradigma da teoria crítica como um dos quatro paradigmas conviventes na produção científica hodierna nas ciências humanas e sociais. Para ele, na teoria crítica, a pesquisa é uma ação política: sua ontologia é a de um realismo crítico e sua epistemologia, subjetivista, uma vez que as ações de pesquisa estão nela consideradas como intimamente relacionadas aos valores de investigador, requerendo um método dialógico e transformador, por meio de desvelamentos e desvendamentos dos objetos e sujeitos, visando chegar-se à "consciência verdadeira" e facilitando a transformação da realidade. Como uma teoria crítica, deve a mesma ser capaz de auto-reflexão entorno dos próprios fundamentos, ou seja, de explicitar e discutir os seus próprios pressupostos práticos e conceituais. Isso comporta cautela crítica em confronto com as metodologias pré-constituídas e, ao mesmo tempo, a idéia de uma sociedade emancipada como referência (Tassara, 2006). Assim, enfrentar a crise ambiental sob o enfoque crítico da Educação Ambiental consiste em promover uma forma de pesquisa social, a pesquisa-ação, aplicada de forma incremental e articulada a coletivos educadores, conferindo-se à mesma o sentido de promover uma teoria da sociedade atual como um todo, utilizando-se das diversas disciplinas das quais e sobre as quais se hibridiza a pesquisa social - a 
psicologia social, a psicanálise, a antropologia, a psicologia e a sociologia, as chamadas ciências sociais e humanas.

Em síntese, tal assunção para a Educação Ambiental Crítica significaria, do ponto de vista lógico, a necessária vinculação da pesquisa-ação a uma abordagem condutora de uma identificação participativa de problemas e problemáticas, de uma realização participativa de análises integradas dos mesmos e de uma formulação participativa de respostas compartilhadas e construídas em fóruns temáticos compostos e geradores de elos sociais, baseados $\mathrm{e}$ informados pelas diferentes linhas históricas de conhecimento, nas diferentes normas de produção cultural (Tassara, 2006).

Assim, a Educação Ambiental Crítica, necessitando instaurar a pesquisa-ação, necessita, em decorrência, mobilizar a participação popular, enfrentando silêncios e "silenciamentos" (Santos, s/d) impedidores da abertura de espaços verdadeiros de locução (Habermas, 1987). Isso posto, decorre, como corolário, que qualquer pesquisa em Educação Ambiental Crítica terá de se basear na mobilização participativa dos membros dos coletivos envolvidos na pesquisa-ação, uma estratégia utópica de caminhos, determinando a necessidade de que suas instâncias condutoras analisem e intervenham sobre silêncios e "silenciamentos" que, no seu transcorrer, ocorram na direção da produção de sua utopia-fim, a criação de espaço social promotor de livre expressão.

Sob tal perspectiva metodológica e tendo em vista contribuir para o desenvolvimento competente de pesquisas comprometidas com uma Educação Ambiental Crítica, discorreremos a seguir sobre alguns elementos que a constituem. Ou seja, sobre participação, como promovê-la, sobre silêncios e "silenciamentos" no processo participativo, como entendê-los para enfrentá-los*.

\footnotetext{
* Os parágrafos que se seguem são transcrições de trechos contidos em texto elaborado para documento técnico pelos autores do presente artigo, documento este intitulado "Mapeamentos, Diagnósticos e Intervenções Sócioambientais" e desenvolvido atendendo solicitação da Diretoria de Educação Ambiental do Ministério do Meio Ambiente.
} 
Participar, como verbo intransitivo, significa "fazer ou ser parte de, associar-se". Nesses termos, o substantivo participação, derivado do verbo participar, implica o ato de se fazer ou ser parte ou, ainda, de se associar.

O uso político do termo participação é, portanto, uma extensão, por analogia, do significado literal do termo, para indicar situações nas quais essa associação ou esse fazer parte aplicam-se à vida social, significando, genericamente, uma adesão ou compromisso com ações inscritas nessa mesma vida, que visa ou não atingir um fim préestabelecido ou identificável.

No primeiro caso, a participação se conduz estrategicamente como um meio para a consecução de um fim ou de um projeto. No segundo caso, na impossibilidade de que a finalidade da participação possa vir a ser identificada, ela se apresenta como um fim em si. Nesta última configuração, haveria duas possibilidades: uma em que aparentemente não se conseguem apreender os propósitos da participação e outra em que os propósitos da participação são a sua própria constituição como dimensão política democrática. Esta última se denomina participação política direta dos cidadãos.

Assim, essa participação política cidadã, quer espontânea ou induzida, pode ser analisada como uma manifestação do teor democrático da vida social, em razão de sua natureza e de como se inscreve nessa mesma vida, demonstrando que, ao sujeito da participação ou ao sujeito indutor da participação, cabem expressões que refletem que os mesmos se consideram, e consideram aos outros, fazendo parte, legitimamente, da vida social, se envolvendo, ou aspirando a se envolver, nos caminhos e destinos da mesma.

A pesquisa-ação, tal como concebida por Lewin (1948), envolve interações sociais centradas na participação democrática dos membros dos grupos e coletivos em questão, ou seja, consiste em uma forma de pesquisa social, politicamente engajada, na qual alguns atores (no papel de condutores, educadores e educandos) deverão induzir a participação de outros atores (no papel de educandos, educadores e condutores) na direção de uma transparência de condução e de uma redução gradativa da indução da participação a par com o incremento 
da participação espontânea. A indução da participação em coletivos dessa natureza evidencia importantes questões relacionadas à formação democrática e à socialização dos cidadãos, sobre as quais gostaríamos de refletir.

Ao refletir sobre esse tema, é essencial não perder de vista, de um lado, os atores envolvidos na construção: o próprio Estado em primeiro lugar, sede do poder planejador das políticas públicas, os cidadãos (individualmente ou enquanto membros de associações, ONG's, integrantes da sociedade civil, etc.) convocados por aquele a participar e os técnicos que, fazendo parte do mecanismo estatal de planejamento, execução e avaliação das políticas públicas, são, ao mesmo tempo, cidadãos desse mesmo Estado, delicada posição nessa dialética do poder e participação, que a todos implica; de outro lado: os processos nos quais esses atores estão envolvidos.

Desse modo, tratar-se-á neste texto de participação emancipatória entendida como a ação de ser (fazer) parte de processos de transformação social que suponham não uma passividade dos atores (convocados de cima e de fora, meros receptores das conseqüências das políticas públicas), mas, pelo contrário, uma ação enquanto agentes do processo em todas as suas fases e para todos os efeitos.

Sob tal perspectiva, é relevante compreender que, perante problemáticas socioambientais, a educação ambiental deve, para produzir mudanças na consciência ambiental (atos de significação sobre o socioambiente), ultrapassar aspectos meramente reivindicativos dos participantes dos coletivos. Nesse sentido, a pesquisa-ação implica, necessariamente, um trabalho de condução de procedimentos voltados para a produção de uma reflexividade crítica de seus participantes (auto-questionamento dos pressupostos das próprias opiniões e ações), que seria o único recurso permitindo sustentar, na condução e através dela, a participação real na pesquisaação, estendendo-a para outros grupos e coletivos (multiplicadores), e tornando-as - participação, pesquisa-ação e reflexividade irreversíveis.

Se a educação ambiental é o objetivo ao qual serve, como método, a pesquisa-ação por meio de coletivos educadores, é mister 
não se iludir a respeito do verdadeiro papel democrático transformador dos participantes, na medida em que, dependendo do ator e da instância do Coletivo Educador no qual se situam, os critérios lewinianos não estarão operando da mesma forma. Isso pelo simples fato de que alguns desses atores, ou dessas instâncias, são ou estão integradas por "representantes" de instituições dos mais diversos tipos e presença na sociedade. Tal situação implica que quem representa, no coletivo, uma instituição não poderá ter - porque submetido aos imperativos da instituição que representa - o grau de autonomia e reflexividade que a pesquisa-ação, por definição, exige.

Constituir coletivos educadores nos quais se pretende trabalhar com o método da pesquisa-ação, então, supõe enfrentar a contradição fundamental de coletivos "representativos", aos quais acabamos de nos referir, e coletivos "populares", ou seja, coletivos integrados por cidadãos, cuja consciência ambiental não pode ser impingida "de fora" e "de cima" de seu contexto vital, pois se isso acontecer, corre-se o risco de a consciência ambiental não aparecer nos sujeitos ou, se já existir, de que ela não se desenvolva ao mesmo tempo em que a consciência política, histórica e social.

Em suma, a educação ambiental dispõe de muitos recursos para se realizar, tanto midiáticos quanto presenciais, mas, se pretender alcançá-la por meio da pesquisa-ação, tal como foi pensada pelo seu fundador Lewin (1948), deve-se tomar a decisão, política e metodológica, de priorizar os coletivos educadores que contemplem a participação direta dos cidadãos, neles, e enfrentar, até onde seja possível, a contradição entre os já mencionados coletivos "representativos" e os "populares".

Colocadas as questões a serem enfrentadas, das turbulências causadas pelas interações entre a participação representativa e a participação popular, evidencia-se uma outra problemática, qual seja, de que maneira, então, induzir a participação em coletivos, ou seja, como planificá-la, uma vez que essa planificação, no que se refere a coletivos democráticos e de problemáticas socioambientais, também deverá se processar de forma participativa, pois implicará intervenções 
visando a construção do futuro social, devendo pautar-se em uma busca de conceituação compartilhada de um bem comum.

Assim, a planificação participativa da pesquisa-ação deverá, ela própria, ser objeto dos mesmos processos envolvidos na planificação do processo de ensino-aprendizagem entre atores nos papéis de educando e de educador, além de ser regida por todos os elementos que compõem as circunstâncias presentes na análise de atividades envolvendo interação social, condicionando seu desempenho.

Portanto, a planificação participativa pressupõe a eficácia de seu projeto na produção de uma articulação adequada entre o plano por ela desenvolvido e a participação dos coletivos populares aos quais se dirige e cuja participação, se induzida, deverá vir a se tornar espontânea.

Se a política ambiental pode ser pensada, em uma configuração democrática, como a construção compartilhada do futuro social, a questão nodal que se coloca, para os governos democráticos em regime representativo, é que eles devem se pautar pelo envolvimento participativo máximo da sociedade na definição de suas ações de governo, o que, mais uma vez, traz à tona a questão da participação representativa e a participação popular.

Esse compromisso político-analítico implica que a planificação das intervenções socioambientais deve efetuar-se por meio de coletivos "educadores-planificadores-avaliadores".

A arquitetura da capilaridade, articulando setores planificadores com setores que serão sujeito (e não objeto) das planificações, só será ético-democrática se pressupuser a transformação de qualquer membro do coletivo em um planificador e, portanto, em um co-governante que se auto-representa nos coletivos e que, no limite utópico, exauriria a distinção entre democracia representativa e democracia popular.

Por outro lado, em um coletivo-educador, espera-se que seus membros participem, ou seja, que, além de presentes fisicamente, se expressem sobre os assuntos em pauta. Dessa forma, como compreender os silêncios de participantes no coletivo ou do próprio coletivo? Como atuar quando, no papel de condutor de fóruns participativos, as falas de seus membros não se produzirem? O que 
significa o silêncio de um sujeito, em tais circunstâncias? Essa é uma complexa problemática que requer análises de dimensões lógicas, psicológicas, psicossociais e políticas que tentaremos esboçar a seguir. Pode-se distinguir, do ponto de vista lógico, duas situações psicológicas emblemáticas como sustentadoras de um silêncio.

Em uma primeira categoria, estariam os silêncios produzidos pelo aparente desinteresse e não-motivação em relação às temáticas em discussão, ou seja, haveria um desencontro entre os procedimentos de problematização e/ou questionamentos aplicados e o mundo interior desses participantes. Esse não-encontro poderia ser explicado pelo fato de que os conteúdos, e/ou as formas, implícitos no agir educativo, não se compatibilizaram com as experiências do espaço vital dos indivíduos, produzindo ou mantendo um afastamento da atividade, da significação que ela pode vir a ter para os sujeitos. Em outras palavras, estar-se-ia perante um sujeito que pode ser caracterizado como distraído ou apático em relação ao processo coletivo; mas isso não significa que esse sujeito não esteja interiormente ativo, dialogando com outras associações mentais de natureza variada, as quais ele não está comunicando ao coletivo. Diante desses silêncios, caberia ao coletivo tentar articular estratégias comunicativas visando estabelecer um diálogo produtivo o suficiente para estimular a expressão efetiva dos sujeitos silenciosos, quebrando o isolamento que tal silêncio perpetua, excluindo-os da participação. $\mathrm{O}$ chamado método Paulo Freire, aplicado à educação popular, consiste em um conjunto de procedimentos a serem utilizados visando-se impedir a exclusão das atividades por silêncios desse tipo.

Em uma segunda categoria, haveria o silêncio substrato de uma reflexão em curso, reflexão esta que pode estar sendo produzida a par com o desenrolar das interações sociais no interior do coletivo, em maior ou menor grau de indução ou de espontaneidade. Esses silêncios se relacionam, também, com atributos de personalidades mais ou menos introvertidas, cabendo às instâncias condutoras do coletivo buscar o entendimento comunicativo dos mesmos a fim de distinguilos dos que fazem parte da primeira categoria. Isso implica uma capacidade de leitura desses silêncios, efetuada por intermédio de 
outras linguagens, principalmente as não-verbais (expressão facial, gestos, posturas, etc.).

Tanto na primeira como na segunda categoria, o pensamento, o mundo interior do sujeito, se estrutura sobre instantes de significação, aquilo que Piaget (1968) denomina de estados de consciência, os quais, por arbitrárias associações livres ou por reflexão intencional (reflexividade crítica), estão limitados às condicionantes que seu processo de socialização determina.

Tais condicionantes situam-se na esfera psicossocial e vão implicar impedimentos para as manifestações, quer produto da intenção de refletir, quer produto da livre associação intuitiva. Ou seja, a criação do pensamento se faz em função das experiências socializadoras às quais o sujeito foi submetido no transcorrer de sua biografia.

Podem ser identificadas quatro fontes de tais condicionantes, que se manifestam em ambas as categorias psicológicas de silêncio: a ignorância, o impedimento psíquico, a arbitrariedade semântica e a alienação política.

O silêncio pode ser a expressão de uma ignorância (desconhecimento de informações) sobre uma temática: as informações são necessárias para se produzir noções, conceitos e argumentos a seu respeito. Essa característica é denominada pelos lógicos de positividade lógica (Caorsi, 1994), uma vez que, diante do desconhecimento da existência de alternativas de pensamento em relação a um dado objeto, tudo se passa como se essas alternativas não existissem. Produz-se, assim, ante a ausência de uma alternativa, uma não-realidade de tal alternativa. Muitos movimentos de exclusão implicam, para as pessoas, o não oferecimento (ou escamoteamento) de informações e, portanto, da possibilidade, com base nelas, da percepção de alternativas e de sua conseqüente operação cognitiva, em face da arbitrariedade dos caminhos de pensamento relacionados à análise de uma dada temática.

Por outro lado, há uma espécie de condicionante que se refere ao que a psicanálise denomina de negatividade psicológica (Freud, 1925; Dor, 1988), uma constrição ao exercício da reflexividade pelo 
sofrimento gerado pela negação da ordem estabelecida, que coloca obstáculos para a emergência da consciência, dificultando-a ou impedindo-a. A isso chamamos de impedimento psíquico.

Assim, a positividade lógica diz respeito à origem da alienação na ignorância, ou seja, na ausência de informações que nunca foram apresentadas ao sujeito. $\mathrm{O}$ desconhecimento das informações não permite que elas sejam negadas ou substituídas por outras: não há o "não" (inviabilizando a negação). Já no que se refere à negatividade psicológica, ou seja, quando o sujeito está sob o impedimento psíquico, a situação de alienação ou de silêncio não é produzida pela ausência do "não", mas pela incapacidade de o psiquismo do sujeito suportar o confronto com sua história, com sua identidade. Trata-se de uma forma de alienação que não vem da ausência de informação, mas da impossibilidade de que esta opere no raciocínio do indivíduo.

O silêncio, resultante da ignorância e/ou do impedimento psíquico, é aparentemente o mesmo, mas a sua produção deriva de caminhos diferentes, requerendo, portanto, procedimentos específicos para o seu enfrentamento, visando-se a transformação de situações não razoáveis (silêncios) em situações potencialmente racionais (discursos). No primeiro caso, alienação por ignorância, via oferecimento de informações necessárias identificadas como ausentes; no segundo caso, alienação por impedimento psíquico, por meio de um trabalho de desconstrução (desmonte) racional de processos avaliados como sustentadores de perdas psicossociais e afetivas (elos e vínculos sociais), ocorridas ao longo do processo de socialização dos sujeitos em pauta, atividade que poderia vir a contribuir para a recuperação de seu sentido.

Essas considerações são baseadas no pressuposto de que a identidade é um processo dinâmico que relaciona a história do sujeito, os elos sociais dos quais ele é portador e um tempo arbitrário, refletindo os modelos sociais e suas simbologias, modelos esses aos quais o sujeito teve acesso na constituição de sua condição humana. $\mathrm{Na}$ medida em que o coletivo pudesse se ocupar do enfrentamento dessas formas de alienação, estaria se constituindo em uma clínica psicossocial da identidade (Ardans, 2001), instância voltada para o 
esclarecimento crítico e a transformação da falsa consciência em uma consciência veraz do real ou uma consciência crítica.

O enfrentamento dessas formas de alienação vai oferecer, ao coletivo, possibilidades de conhecimento da existência de diferentes formas de pensar o real e da variabilidade com que as histórias sociais da constituição dos sujeitos dos grupos determinam visões sobre esse mesmo real; ou seja, o real é uma construção social e, como tal, contingente e arbitrário (poderia ser de outra forma).

Tal arbitrariedade não significa o não condicionamento desse real ao próprio processo de socialização do sujeito que o pensa, mas, sim, sendo o pensamento uma função da sua constituição como sujeito, oferece ao mesmo alternativas diferentes para os participantes do coletivo, surgidas das minorias e das diversidades (cultural, social, étnica, lingüística, etc.) presentes entre seus componentes.

Assim, a vivência de um coletivo genuinamente comprometido com a utopia da democracia radical implica a constatação da arbitrariedade semântica com que o real pode ser lido, bem como das verdades contidas nas afirmações sustentadoras de argumentos sobre essa mesma realidade. As práticas, estratégias e discursos dos coletivos são uma função da própria história de constituição desses coletivos, abrindo para a diversidade e a polivalência de noções, conceitos, argumentos e verdades. A ignorância dessa possibilidade plural, acima referida, gera uma forma de positividade lógica que implica o desconhecimento de múltiplos, diversos e contraditórios significados sociais e lingüísticos, sustentando uma forma de alienação específica, qual seja, a da gênese (origem) e a da genealogia (filiação) das práticas e linguagens sociais.

Ainda a esse respeito, pode-se identificar uma outra forma de alienação: a alienação política, aquela que é produzida, segundo B. de Sousa Santos, por "realidades ausentes por via de silenciamento, da supressão e da marginalização, isto é, as realidades que são ativamente produzidas como não existentes". (Santos, s/d, grifos nossos) Ou seja, de acordo com as conceituações acima oferecidas (com exceção da alienação por ignorância produzida por isolamento não intencional), todas as formas de alienação identificadas podem ser consideradas 
como formas de alienação política geradas pela exclusão e pelo domínio subjugador no transcorrer da socialização e da constituição da identidade.

Sob tal perspectiva, a alienação política:

“ (...) delimita um campo de forças sociais em conflito tendo em vista interesses de aproveitamento do patrimônio material e não-material comum às humanidades da Terra. As forças em conflito visam a exercer influências imediatas sobre a construção da sociedade, plasmadas segundo seus interesses determinados, particulares e setoriais, portanto, seus interesses não-generalizáveis e nem tematizáveis na esfera pública. Velados os verdadeiros conflitos, corporificam-se os mesmos na colocação em movimento de forças de informação, contra-informação e desinformação estratégicas, as quais, com maior ou menor grau de sistematização, objetivam influenciar as formas de representação da realidade histórica compartilhadas pelos diferentes grupos sociais, na luta pela imposição de uma alternativa como solução. Assim, a esfera da opinião pública, alargada de fato contemporaneamente pela difusão da informação nas mídias eletrônicas e por suas conseqüências sobre as relações humanas, políticas e sociais, esvazia-se de poder: de um lado mantém latente a natureza particular dos interesses em conflito que se concretizam em imposições de caminhos alternativos; de outro, produzindo a propagação velada de interesses, reduz a participação dos cidadãos à aclamação de escolhas políticas pré-confeccionadas.” (Tassara e Damergian, 1996, p. 297)

O enfrentamento da alienação política nos coletivos supõe, portanto, o questionamento, via racionalidade, do processo suprareferido, desconstruindo sua produção. Tal processo de desconstrução implica a necessidade de ruptura dos silenciamentos por meio de uma arqueologia virtual do presente (Santos, 1995), ou seja, da descoberta dos fundamentos do domínio implícitos nas leituras contingentes do real, em vista de seus componentes histórico-culturais, aí incluindo os encontros civilizatórios nos territórios, ou seja, no socioambiente. 


\section{Referências Bibliográficas}

ARDANS, Omar (2001) Apontamentos sobre a metamorfose humana. Um ensaio de Psicologia Social. Tese de doutorado em Psicologia Social. São Paulo: PUCSP.

CAORSI, Carlos E. (1994) Lógica, filosofia y psicoanálisis. Montevideo: Roca Viva.

DOR, Joël (1988) L'a-scientificité de la psychanalyse. Paris: Editions universitaires. 2 vol.

FREUD, Sigmund (1925) “La negación”. Obras Completas. Trad. José Luiz Etcheverry. Buenos Aires: Amorrortu. 1979, vol. XIX, p. 253-257.

GUBA, Egon (ed.) (1990) The Paradigm dialog. Califórnia: Sage.

HABERMAS, Jürgen (1984) The Theory of communicative action. V. II: Lifeworld and system: A critique of a functionalist reason. Boston, Beacon Press, 1987.

LEWIN, Kurt (1948) Problemas de dinâmica de grupo. Trad. Miriam Moreira Leite. São Paulo : Cultrix, 2a. ed. 1973.

PIAGET, Jean (1968). Le structuralisme. Paris, P.U.F..

SANTOS, Boaventura de S. (s/d) "Para uma sociologia das ausências e uma sociologia das emergências" Disponível em: http://www.ces.uc.pt/bss/ documentos/sociologia_das ausencias.pdf - acesso em 07/06/2006. . (1995). Pela mão de Alice. O social e o político_na Pós-modernidade. São Paulo, Cortz

TASSARA, Eda T. de O. (2006) A Psicologia Social e o Enfrentamento da Crise Ambiental. Texto apresentado em Prova de Erudição para a obtenção de título de Professora Titular junto ao Departamento de Psicologia Social e do Trabalho do Instituto de Psicologia da Universidade de São Paulo. e DAMERGIAN, Sueli (1996) "Para um novo humanismo: contribuições da Psicologia Social" in: Estudos Avançados, USP, 10(28), p. 291-316.

e ARDANS, Omar (2006) Mapeamentos, diagnósticos e Intervenções Sócioambientais. Documento Técnico. Brasília: Diretoria de Educação Ambiental do Ministério do Meio Ambiente. 